\title{
Reflecting, Iterating, and Tolerating Ambiguity: Highlighting the Creative Process of Scientific and Scholarly Research for Doctoral Education
}

\author{
Amanda E. Cravens, \\ Stanford University, \\ Stanford, CA, USA
}

acravens@stanford.edu

\author{
Marilyn Cornelius \\ d.cipher pathways LLC, \\ Palo Alto, CA, USA
}

mc@dcipherpathways.com

\author{
Nicola Ulibarri \\ Stanford University, \\ Stanford, CA, USA
}

ulibarri@stanford.edu

\author{
Adam Royalty \\ Stanford University, Stanford, \\ CA, USA
}

adam@dschool.stanford.edu

\section{Anja Svetina Nabergoj, University of Ljubljana, Ljubljana, Slovenia}

anja.svetina@gmail.com

\begin{abstract}
Material published as part of this publication, either on-line or in print, is copyrighted by the Informing Science Institute. Permission to make digital or paper copy of part or all of these works for personal or classroom use is granted without fee provided that the copies are not made or distributed for profit or commercial advantage AND that copies 1) bear this notice in full and 2) give the full citation on the first page. It is permissible to abstract these works so long as credit is given. To copy in all other cases or to republish or to post on a server or to redistribute to lists requires specific permission and payment of a fee. Contact Publisher@InformingScience.org to request redistribution permission.
\end{abstract}

Abstract

Producing quality original research requires advanced analytic skills, but also the creative intelligence to design a project as well as the ability to handle the inevitably ambiguous research process. This study unveils important aspects of how successful interdisciplinary scholars understand their research process and how they mentor students through research. Using interviews with nine faculty members and qualitative analysis of classroom sessions, the study investigates the mindsets and behaviors that experienced scholars bring to their work. Results suggest that innovative faculty see creativity as central to their research and actively seek to balance the creative and analytical aspects of their work, use an iterative "learning by doing" approach to refining questions and methods, and view setbacks as opportunities for further learning. However, faculty varied in the extent to which they made this messiness and comfort with ambiguity explicit for their students. By uncovering the mindsets that scholars bring to their research, we hope to better support doctoral students in building not just their analytical but also their creative capacity.

Keywords: creativity, reflection, mentoring, advisors, research process 


\section{Introduction}

Learning to conduct original research is a complex process. In the course of earning a doctoral degree, students gradually transition from a dependent phase where a professor provides ongoing feedback (e.g., through taking courses) to conducting independent research that results in an original dissertation project (Lovitts, 2005, 2008). Making the transition from advanced student to independent scholar is not easy (Gardner, 2008; Spaulding \& Rockinson-Szapkiw, 2012). Producing quality original research certainly requires advanced analytic skills, the creative intelligence to design a project, and the ability to handle the inevitably ambiguous research process (Lovitts, 2005). This need is particularly pronounced for interdisciplinary graduate students who must integrate the cultures of multiple disciplines (Strober, 2011), though given the increasingly interdisciplinary nature of much research conducted today (Boyack, Klavans, \& Börner, 2005; Morillo, Bordons, \& Gómez, 2003; Van Leeuwen \& Tijssen, 2000; Van Raan, 2000) this applies to most doctoral students to a certain extent.

Guiding students through the transition are doctoral advisors and supervisors: experienced researchers who successfully completed the $\mathrm{PhD}$ and who simultaneously serve as teachers or coaches who mentor the students to learn the skills of research (Chan, 2008) and as gatekeepers who ultimately decide whether and when the students have proven themselves as scholars (Weidman, Twale, \& Stein, 2001). Mentoring is a critical component of student development (Castro, Garcia, Cavazos, \& Castro, 2011), and can improve the quality of student research (Mohan, 2010) as well student self-efficacy (Anderson, Cutright, \& Anderson, 2013) and socialization into a discipline (Gardner, 2010). However, while "exemplary" mentors interact extensively with students and use a range of modalities to help their students develop (Barnes \& Austin, 2009), students without strong mentoring might flounder in discovering how to do innovative, creative research.

Over the last three years, the authors have taught creative problem solving workshops to doctoral students from across our campus. During these workshops, we have heard many stories from bright, motivated, and despairing doctoral students that suggest that while students have plenty of intellectual mentorship, they are not receiving sufficient guidance on managing the creative flow of their individual research processes or developing resilient emotional attitudes towards setbacks, both of which have been identified as critical characteristics of successful PhD students (Lovitts, 2008). Our observations imply that many research advisors are not adequately mentoring students on what they need to know about the process of doing research. We focus on two potential causes of this lack of mentoring. On one hand, experienced scholars might be unaware of the details of their creative decision-making process, making it much more difficult to coach students through that process. This would suggest that by uncovering that process, we might be better able to explicitly communicate what it is that successful researchers do. Conversely, advisors might be aware of their process, but are ineffectively communicating it to students. This would suggest that additional training in how to mentor doctoral students would be helpful.

This study explores these hypotheses via two research questions. The first is about researchers' own scholarly practice: How do successful interdisciplinary researchers understand their own research process, and how do they deal with the creative aspects of this process? The second is about their mentoring practice: How do advisors mentor their doctoral students to understand the role of creativity in research? Using interviews and qualitative analysis of classroom sessions, we investigated how nine experienced interdisciplinary scholars at Stanford University (a) conceptualize and experience their research process, in particular the creative aspects of it, and (b) how they approach their role as advisors to their doctoral students. Interdisciplinary scholars were chosen as they provide a "critical case" (Flyvbjerg, 2006) as those most likely to be aware of their research process and explicitly mentor it for their students, given the way interdisciplinary scholarship requires explicitly articulating the assumptions underlying one's research. 
This study unveils important aspects of conducting research that are often not explicitly presented in doctoral education. The interviews with leading scholars help us unpack and map their research process with the focus on the central role of creativity in scientific research. Additionally, they uncover elements that might be necessary in order to be a successful advisor and mentor to doctoral students. The implications of this paper are twofold. First, it presents a more holistic view of the research process, which will be useful in developing courses for doctoral students. Second, it provides guidance for junior advisors who are looking for ways to build their mentoring capacity.

We begin with reviews of the literature on reflective practice and on creativity in research. We then introduce our research methods, followed by our findings regarding scholars' research process and mentoring practices. We conclude with additional research needs and implications for the training of doctoral students.

\section{Researchers as Reflective Practitioners}

In analyzing scholarly research processes and mentoring practices, we consider scholars to be reflective practitioners. According to Donald Schön (1983), one of the first theorists who conceptualized reflective practice, a number of professions engage in a continual, dynamic process of assessing a situation based on prior experience while using that situation to update one's expertise, using this accumulated knowledge to find and solve a problem. The essence of professional expertise, therefore, is not just skill in problem solving, but in problem framing (Schön, 1983, p. 40).

Considering the core tasks required to manage a successful research project or program -identifying novel yet tractable questions, developing a research approach that will answer the question, and refining that approach in light of obstacles or new directions - implies that researchers and scientists should be considered reflective practitioners. Innovation is essentially the same whether in science, the arts, or business (Beveridge, 1980; Sawyer, 2006), as research requires an iterative series of problem-finding and problem-crafting. Moreover, the growth of interdisciplinary, multidisciplinary, and other forms of collaborative "team science" (Stokols, Hall, Taylor, \& Moser, 2008) requires managing social relationships and multiple approaches to knowledge to a degree that was rarely required a generation ago, increasing the number of potential design elements to consider and thus making reflection especially critical. Indeed, Schön (1983) himself suggests that scientific research should be considered reflection-in-action: "We may also consider science as a process in which scientists grapple with uncertainties and display arts of inquiry akin to the uncertainties and arts of practice" (p. 49).

Reflection can also be a means of developing professional competence (Lyons, 2010; Schön, 1990). Scholars and educators in fields as diverse as teacher training, legal education, clinical psychology, nursing, and public management (e.g., Broussine \& Ahmad, 2013; Bulman, Lathlean, \& Gobbi, 2012; Davis, Thwaites, Freeston, \& Bennett-Levy, 2014; Evans, 2013; LaBoskey, 2010) have used reflection to support budding professionals to develop the mindsets required by their professions. While novices certainly can learn from experience alone, coaching to reflect on the meaning of experience can greatly improve the effectiveness and/or reduce the emotional discomfort of the learning process (Schön, 1990). This suggests that reflection may also be an important part of the mentoring process for doctoral students.

\section{Creativity in Research}

Creativity in science refers primarily to the generation of original knowledge (Heinze, Shapira, Rogers, \& Senker, 2009; Hollingsworth, 2012; Simonton, 2004), and has long been recognized as essential for research (Council of Graduate Schools in the United States, 1977) because novelty is what expands the boundaries of knowledge.

Empirical examinations of creativity generally take one of four main approaches: identifying the traits of creative individuals, studying the products that result from creative work, exploring the process of 
creativity, or examining the institutional context in which creativity occurs (Heinze et al., 2009). Much research on creativity in science uses outcomes like publication citations (Simonton, 2004) or prize winners (Hollingsworth, 2002; Zuckerman, 1996) as proxies for creativity. Because universities and funding agencies want to understand how best to support scientists to make the next breakthrough discoveries, another common approach are studies of research environments' influence on scientists' creative output (Heinze et al., 2009; Hemlin, Allwood, \& Martin, 2004). How scientists experience the creative process of scholarly research, which we investigate in this paper, is less studied.

Developing a creative mindset is particularly important for the success of graduate students. Barbara Lovitts' (2008) study of factors contributing to graduate student success suggested that "creative intelligence" was a key distinguisher in determining how successful graduate students were at making the transition to independent scholars (pp. 304-305). However, as Lovitts (2005) observed, creativity is rarely taught: "Despite the apparent importance of creativity in graduate education, it is typically assumed that creativity is idiosyncratic and that advisers can do little to help their students develop into creative scholars" (p. 141). While certain exceptional advisors or courses (e.g., Cash \& SanchezHucles, 1992) focus on the creative confidence (Kelley \& Kelley, 2013) needed to navigate what students can initially experience as a chaotic process, by and large graduate students appear to be taught research design as a linear series of steps (the scientific method or equivalent) that provides an insufficient map to guide emerging researchers through the complexity of doing independent scholarship. We therefore seek to uncover researchers' creative process so that it can be better communicated to graduate students.

\section{Methods}

We qualitatively explored the research practice of successful interdisciplinary scholars at Stanford University (Stanford, California, USA), focusing on how they conduct their research and how they mentor their doctoral students. We chose a qualitative approach because creativity is so difficult to quantitatively categorize (Heinze et al., 2009). Our study addressed two specific research questions:

1. How do researchers conceptualize their own research practice? In particular, what mindsets and behaviors do they consciously adopt to manage the creative aspects of their research process?

2. How do researchers mentor their interdisciplinary doctoral students? To what extent do they consciously model or explicitly coach students regarding the creative process?

\section{Study Participants}

Study participants were nine researchers at Stanford University. These nine professors represented a range of academic disciplines from across the campus, including humanities, engineering, medicine, law, and physical and social sciences, but all are affiliated with campus interdisciplinary initiatives. We refer to their general area of scholarship and not their specific discipline in order to protect anonymity. Their career stages at the time of the study ranged from pre-tenure assistant professors through full professors with many years' tenure at the university. The study participants were both male and female but in order to protect anonymity, we refer to all interviewees as "he" regardless of

gender. For the same reason, designations of rank are simplified to "junior" for pre-tenure faculty and "senior" for tenured participants.

Rather than aiming for a representative sample, our nine faculty participants were purposely selected for their reputations as innovative interdisciplinary scholars conducting research with real-world relevance. These faculty had been invited to participate in a research design seminar for $\mathrm{PhD}$ students in an interdisciplinary graduate program, signaling both an established reputation as quality researchers in their fields and an interest in mentoring graduate students. These scholars thus represent what Bent Flyvberg (2006) calls a critical case, one that has "strategic importance in relation to the general prob- 
lem" (p. 229). If any scholars can be expected to display awareness of their own research process, it should be the most innovative scholars working with collaborators in other departments and partners outside of academia, since interdisciplinary research requires working between the boundaries of disciplinary cultures and frequently articulating the assumptions of ones' own disciplinary lens in a way not necessarily required when working within a single discipline (Strober, 2011). Additionally, since our sampling strategy utilized a seminar where faculty were hand-picked for their reputations as innovative scholars with the ability to discuss their research with students, we were ensured of studying a group with the highest likelihood we could find of including both innovative researchers and successful mentors. It is important to note that our selection was only on the basis of reputation, not on any objective measures of self-awareness or mentoring ability. Moreover, given the critical case approach, our findings about research process or mentoring may not be generalizable to noninterdisciplinary scholars. If we find minimal evidence of self-awareness or mentoring skill, we would expect those patterns to hold for other non-interdisciplinary scholars, but the reverse may not be true.

\section{Data Collection}

Our study had two interwoven stages. First, in the Spring of 2011 we videotaped sessions of a research design seminar for interdisciplinary $\mathrm{PhD}$ students. Unlike many conventional research design and methods courses, this seminar is specifically designed to expose students to the real-world narrative behind interdisciplinary projects that one cannot glean by simply reading the published papers' version of events. This seminar is known for enabling candid discussions with faculty about how specific projects germinated and progressed as well as providing an intimate window into how innovative scholars approach their work. Guest speakers in the seminar vary from term to term, but are always selected from among the most innovative interdisciplinary scholars on campus and intentionally include dynamic faculty well-suited to discuss their research with students. We obtained permission to video record the seminar for the full term, recording a total of 10 weekly sessions, featuring 9 guest faculty speakers and over 15 hours of classroom discussion.

Table 1: Follow-up Interview Protocol

1. How do you come up with ideas for a new research project?

2. Once you've developed a new idea, can you walk me through the stages of your research process?

3. How much does your process vary by project? What does the variation depend on?

4. What do you do when you are feeling stuck in research?

5. Imagine you have a new interdisciplinary graduate student you've agreed to advise. How will you mentor and advise them to do excellent interdisciplinary research? Is your approach different than for a disciplinary graduate student (if so, why? how? if not? why?)

6. What specific aspects of the research process do you talk to your students about or demonstrate for them?

7. Thinking back on your answer to the last question, how would you describe your overall approach or philosophy for training your students to conduct research? How has your approach evolved since you were a new teacher?

8. What approaches or mindsets toward interdisciplinary research do you try to cultivate/instill in your students? Is this the same as what you do in your own research? Or different? Why?

9. How do you think about the relationship between creativity and research?

In the study's second phase, we conducted individual follow-up interviews with each faculty member who had presented in the seminar to better understand their research as well as mentoring process. While one of the advantages of analyzing classroom discourse is the natural, unfiltered dialogue that occurred, one drawback is that different seminars addressed different issues to varying extents. Based on the results of our initial analysis of the seminar conversations, we developed a semi-structured in- 
terview protocol that allowed us to obtain consistent data on key emerging themes across our nine participants (see Table 1). Questions focused on how the researchers approach their research, particularly how they generate ideas, what they do when feeling stuck, and how they move from an initial idea to project completion. We also included questions about how researchers mentor their students. Follow-up interviews of 30-75 minutes in length (approximately 400 minutes in total) were then conducted with each participant using this protocol. Two of our research team members were present for each audio-recorded interview. Note that we did not mention or discuss creativity until the very last question, unless the participant mentioned it first, to avoid priming participants.

\section{Data Analysis}

Using a thematic analysis approach (Guest, MacQueen, \& Namey, 2011) and the collaborative web video tool DIVER (Pea et al., 2004), videos from the seminars were initially open-coded for emerging themes (e.g., serendipity, risk) as well as coded for mindsets and behaviors known to be important to the creative process of other reflective practitioners such as product designers (e.g., iteration, tolerance for ambiguity). Each video was coded independently by at least two members of our research team.

Interviews were initially coded using the same coding scheme as the seminar video recordings. Additional themes were added as needed; seminar videos then were re-coded using these additional themes. Our results reflect findings from both the seminar videos and the follow-up interviews; quotes are taken from both phases of the project.

\section{Findings}

\section{Mindsets and Behaviors Displayed by the Researchers}

The collected data yielded a rich picture of mindsets and behaviors that scholars use in their research process. As our participants described it, research requires a creative phase of design followed by an analytic phase of implementation, can take much iteration, and should be expected to go in unexpected directions.

\section{A time to be creative and a time to be analytic}

The scientific creativity literature leaves no doubt that creativity is an integral part of research (Heinze \& Bauer, 2007; Heinze et al., 2009; Heinze, Shapira, Senker, \& Kuhlmann, 2007). Our respondents reinforced the view that scientific research and creativity are deeply interlinked. One of the participants stated that "creativity is at the heart [of the research process]" and "a part all the way through." Another emphasized, "There's no separateness, there should be no separateness [between science and creativity]." A third stated that creativity is a "critical mindset that is absolutely essential to the research process at every stage," adding:

"I can't imagine doing research without being creative. I feel like creativity is at the core of research. Creativity is what helps you formulate your questions, it's what helps you think about the methods you're going to use, it helps you come around if you come across any blocks, helps keep you motivated. When you come to having your results and findings, creativity is what helps you interpret those findings, it's what helps you apply the findings, and it seems to me that it's at the core of everything."

A fourth participant provided further support for this view of research and creativity as inseparable: "There's almost no good research that's not creative... There's a certain minimal level of technical excellence that I think is required to succeed in doing research, but beyond that I think people who are really successful far and away are the creative ones." A fifth poignantly summed up the link: "Scien- 
tific research is my primary form of creative self-expression...it has essentially squashed all other forms I ever had."

Our participants emphasized that science results from a dynamic interplay between analytic thought and creativity. As one of our interviewees explained: "We have this myth that creativity is somehow inspired, comes to you in a flash [but that's not how it really happens]. Those flashes do happen in intellectual work, but it doesn't happen in a vacuum. In $99 \%$ of the cases, people don't have flashes of creativity without having done backbreaking work before." On the other hand, the scholars reported that the scientific community can overemphasize the importance of the hard analytic work at the expense of recognizing the role of creative intuition. One of our interviewees who does research in a physical science field revealed that he used to hide his creativity and just be rational but later in his career realized that "letting my intuition speak is at the heart of doing good research." He explained further that his analytic thinking is motivated by a desire to prove what his intuition suggests: "scientists don't like to admit it but [there is a] strong artistic or poetic element [in science]...[you] have aesthetic patterns in your mind and that's what you try to translate out into science."

According to our participants, the most fertile period of creativity in research comes up front, as our participants believed the most creative part in doing research is the study design phase, when they are asking new questions or framing problems in unique ways. One of the scholars emphasized this research design phase is where "there will be a big difference between a creative person and a less creative person...as a creative person you see if you can have a special angle of attack." The rigorous and rational aspects of science only follow when one has a well-framed question and procedure.

Most of our participants view developing that "special angle" on a question as a creative process that lies at the heart of doing innovative science. One researcher emphasized: "Only those that are deeply creative come up with interesting research questions." Another scholar defined creativity in research as "asking the wacky questions." Similarly, another participant said he is often asked what his value as a researcher is and his typical response focuses on asking innovative questions:

"I think I find different questions, I find new ways of answering them... I put essentially all of my energy into finding what we don't know about how the world works and what's important about what we don't know and how to learn it. It includes curiosity, includes figuring out how to solve a problem, and I think there's a creativity in posing the questions and figuring out what to pursue that's partly curiosity but partly seeing the world in a unique way."

By asking new questions, he is bringing his own unique contribution to the research.

The scholars viewed designing innovative research methods to be as essential as coming up with new research questions, as one scholar nicely summarized: "Ideas are a dime a dozen. It's easy to have an idea. But to figure out how to do it is priceless." Another participant pointed out that he "forces himself to spend the most time" framing the research question since "I know by experience if this is not very well done it can derail completely the whole thing". A third researcher's perspective of creativity includes considering a problem from unique or unexpected angles:

"When you see a paper in Science or Nature...what gets you into Nature...you're asking a question that we've been wondering about for a long time but you're doing it in a way that's extremely creative in terms of using datasets that are out there or going after data and I think that is a real skill."

Methods as well as research questions can be important creative contributions in the research design phase of a project.

\section{Perpetually learning through iterative action}

Our study participants approached both the creative and analytic phases of their research process as an experimental, iterative process of taking concrete actions with the expressed intention of learning 
something to allow one's thinking to progress. In the creative phase, iteration was generally focused on framing and reframing questions and iterating study designs and methods. Then, as the scholars proceeded with the analytic work of the research, they continued to use "learning by doing" methods to make progress. Even those using qualitative methods utilized successive combinations of adductive ("what is the best explanation for what I am observing?") and deductive or inductive reasoning. Like innovators in other domains such as engineering or software design who use prototyping, pilots and user testing to advance their thinking (Brown, 2008; Nussbaum, 2004), the researchers described a variety of concrete methods for iterative "thinking by doing" or "learning by doing" that allowed continual learning throughout their research process.

Our study participants utilized a range of techniques to develop new research questions and methods, depending on their research disciplines, but all relied on an exploratory mindset that one termed "being open to the possible". These scholars did not describe clear starts and ends to individual projects. Rather, as experts in their respective fields, their research agendas comprised a fluid problem space within which they were constantly identifying interesting potential research questions, only some of which they will ultimately pursue. Two participants described finding research questions when their academic reading revealed gaps between theoretical explanations that existed in the literature and what they had observed in their own lives. Another had started projects based on "one line in the newspaper" that triggered an idea.

For those researchers whose work focused on human systems, the initial framing of a new project often began with understanding their research subjects' experience from the subjects' point of view. One anthropologist described his ideas as arising from real life, particularly his longstanding relationships with the community where he conducts research and the questions that they care about. He then reframed the community's interests into academic questions that can simultaneously contribute to anthropological knowledge more generally. An education scholar conducted pilot studies using ethnography and participant observation to reveal surprising ideas and hypotheses he might not have otherwise considered. A third example was a public policy researcher, who described his approach to project development as having a "beginner's mind" and "learning from the people in the field" in order to frame a legal or regulatory issue. Most of his projects start with challenges being experienced by real-world users. Even those whose research is not qualitative often framed their inquiry initially through ethnographic-type methods. For example, a medical researcher worked with his clinical collaborators to get ideas for research and-more importantly, since he often develops his research questions after he knows what data exists - obtain access to relevant data.

Sometimes there are significant time delays between the initial idea and the development of a project. One of our participants described how he is constantly having ideas for projects he would like to test from a theory-building point of view but files them away until he encounters the right dataset or partners to bring the idea forward and develop it into a study. He is continually open and curious about the systems he studies, generating many possible ideas and always being open to reframing them to make them more relevant or feasible, but only a few of the ideas get reframed into actual projects. As a result, the ideas he chooses to pursue and spend his analytic energy on have already been through a rigorous selection process and represent some of his highest quality ideas.

A final key to these researchers' creative success in generating innovative questions and methods was their continual willingness to reframe their questions until they found the most appropriate one. While finding questions is a relatively fluid process, the actual question or hypothesis that drives a project might be several iterations away from the initial idea. One senior physical scientist described the process he goes through to move from initial idea to the right question:

"So basically you play and say what if I change the scale, what if I look at this at a finer scale, what if at a courser scale? What if I change the view angle? If there's a conservation issue that was always approached from the viewpoint of the conservationist, what if I look at it 
from the viewpoint of the wildebeest? You try creatively to look at the issue in a way that hasn't been investigated."

In other cases the reframe related to audience, making a question motivated by the real world more relevant for academic audiences or, conversely, translating questions of academic interest to have greater relevance to particular real world cases.

Once they had found the right research question and study design, the researchers continued to use a range of concrete techniques to advance their thinking in small stages. One important category of iterative learning was seeking feedback on early versions or drafts of ideas. For instance, a humanities professor presented his ideas orally first in conference presentations and in classes before developing them into articles. Only once they had been through rounds of feedback as presentations and peerreviewed articles would they eventually be incorporated into the larger structure of a book. A policy researcher similarly discussed ideas orally with colleagues before they appear in articles. Another public policy researcher whose work includes frequent presentations before state agencies and the legislature "ground truthed" testimony with expert colleagues before presenting them publically. In each of these cases, sharing ideas with others and receiving feedback allowed the researcher to advance their own thinking in an informal setting, providing continual learning long before a final, formal output is produced.

A similar process of continual learning happens with a second kind of "thinking by doing" that does not rely on feedback from others. Sometimes, an activity itself provides the feedback a researcher needs for learning to occur. When one participant wrote his first paper using a new analytic technique, his most important learning came not from the feedback he received from others, but from the process of using the method with actual data and imagining how it could be improved for the next project. Another researcher described how he often writes the introduction to his papers first, since doing so allows him to understand for himself exactly what contribution he is aiming to make in the rest of the paper. Similarly, a physical scientist views writing a grant proposal as an opportunity to test for himself what he would need to do in order to satisfactorily answer a given research question. If he is able to write a convincing grant proposal, he knows he has a watertight research design. As an education scholar nicely summed it up, often he "learns just by doing the research....as a learner that's how I learn best." The iterative process of asking a question, designing a way to answer it, and adjusting as the process proceeds provides him with a constant source of new insights and ideas.

\section{Getting stuck is in the eye of the beholder}

The experimental, iterative approach to problem solving observed in our study participants is made possible by their emotional attitudes towards their research process. In contrast to many of the graduate students we have taught, who are often afraid to be perceived to fail even temporarily and are anxious when facing uncertainty, the successful scholars we interviewed appeared comfortable with ambiguity and risk, viewing it as a normal part of the process of producing original research.

Ambiguity tolerance is "the tendency to perceive ambiguous situations as desirable" (Budner, 1962, p. 29). The ability to cope with ill-structured or open-ended situations is a prerequisite for creativity (Tegano, 1990). Lovitts $(2005,2008)$ similarly found that not being afraid of failure distinguished those graduate students who successfully made the transition from dependent to independent phases of their degree. The researchers in our study acknowledged that in order to learn from ill-defined research problems, one has to accept that one does not know everything and sometimes one will fail. These successful scholars view setbacks as something to learn from rather than signs of failure. A humanities professor discussed the difficulties he faced with his last book when the topic emerged with far more "indeterminacies" than he'd anticipated; his broader point was that even with a wellthought-out outline on which others had given him feedback, there is no guarantee that any project will go as planned. He accepts the risk of a project taking years longer than expected as part of the 
nature of his work. Another participant, a physical scientist, emphasized how important it has been for him to learn to thrive on not knowing what the answer is.

Perhaps the most poignant evidence of these scholars' approach to the inherent uncertainty in research was their responses when we asked them what they do when they get stuck. Some of them did not recognize that they ever actually get stuck, or redefined the challenges they experience as outside the definition of stuck. A social scientist stated,

"I don't know if I've ever felt stuck...I've felt that particular things weren't working well or particular components that you'd hoped would be productive weren't, that you end up hitting dead ends on or your collaborations fall through on particular areas, but I've never felt that one of our research projects was starting to get stuck per se."

He then went on to describe how discovering the original data collection method for one project was infeasible and culturally inappropriate led to rethinking the plan entirely (while halfway across the world in the field), but ultimately the new methods

"ended up being far more productive in the end and far more relevant to the research questions.......as I said it's never been the case that a research project has gotten stuck. There's just been lots of occasions where components were not going to work and we just abandoned them or just adjusted to try to get at a different set of questions."

A humanities scholar told us about having what was "not writer's block but does make me pace around the house for a couple of days before I figure out how to do it." An education scholar answered the question this way:

"I don't know that it happens very often...I wouldn't necessarily say we've been stuck...the way we designed this project I actually found this fun but I could see some people finding this uncomfortable is that we've got two pretty distinct theoretical stances on this project [and need to work with both]."

Unlike the doctoral students we have taught, these researchers do not view periods of not knowing what to do next as evidence of personal deficiency.

They generally avoided feeling stuck because they viewed research as a fluid process of learning, adapting, and gaining new insights; any given challenge was simply part of this learning cycle that signaled a need to reassess. A public policy scholar, for example, described feeling stuck as an impetus to examine the underlying framing for the problem: "questioning whether you're asking the right questions is often a good way of unsticking yourself." Similarly, for a humanities scholar, writer's block was often a signal there was a body of research yet to be done. They understood where they are at a given point in time and are able to adjust accordingly, thus maintaining the feeling of being in control and avoiding the feeling of being overwhelmed.

The researchers also reported (to varying degrees) tolerating the risk that a given project might ultimately fail. As one physical scientist summarized, "when you do this risky research some of these paths will lead nowhere; you know it in advance." Researchers' open, iterative, experimental mindset extends from the initial problem-framing phase throughout the entire research cycle. Our participants clearly displayed a learning orientation and growth mindset to their work (Dweck, 2006; Watkins, 2010), viewing each step of their work as a potential opportunity to learn something new. One highlighted that often the lessons are unexpected or surprising: "What I find interesting [at the end of a project] is usually not what I anticipated when I decided to start something." A physical scientist summed up the need to tolerate ambiguity this way: "There is no right way to do [interdisciplinary research]...you have to be willing to not know everything." 


\section{Talking About 'My Research Process' Was Challenging Even For Experienced Researchers}

Particularly in the individual follow-up interviews, the scholars in this study found our questions about how they conduct research fairly to very difficult to answer, or they needed quite a bit of prompting to think about specific example projects to anchor their descriptions. (The classroom sessions were each focused on a given project, so they were by definition anchored in the story of a specific example). Even those (mostly senior scholars, and one junior scholar in the school of education) who were able to speak abstractly about their practice did not seem to have given the topic much previous thought. Most of them also thanked us at the end of the interview for the chance to think about something they rarely (or never before had) considered, which suggests that their hesitant responses weren't due to a faulty question but because it was an unfamiliar topic. Moreover when asked about their process the faculty took long pauses to think, but they had immediate answers when asked about their research topics.

The most extreme example was a junior physical scientist, who replied this way when asked how much the research process varies by project: "Ummm...I guess I don't really know myself well enough to really know and I don't know enough about research process to know well enough." Later in the conversation, the same scholar made a number of comments that gave us interesting insight into the overall trajectory his projects take, but he did not necessarily seem aware of common elements himself.

Other scholars made comments that suggest they assumed everyone conducted research in the same manner. For instance, a junior engineering professor stated that he does it "probably how most people do it, I don't think there's any special magic there." A humanities professor made essentially the same assumption when he said, "when in a research career you just read" when asked how he comes up with new questions.

The ability to reflect about research varied significantly between researchers. Four senior scholars with many years' experience were relatively fluid in talking about research while the five remaining (and more junior) scholars struggled to varying degrees, suggesting that fluidity might come with added experience. However, the small sample size makes it hard to say whether or not years of doing research is the reason for the difference. Overall, we interpret these interviewees' difficulty reflecting about their research process and practice as signaling a lack of metacognitive awareness. Metacognition-knowing about knowing - is a higher order cognitive skill that develops after someone has become conscious of how they know or think about something (Metcalfe \& Shimamura, 1994). In the terms of a common teaching cliché, we might say the researchers are "unconsciously competent" as scholars, displaying a high degree of skill, but not necessarily able to easily translate that skill into words or abstract description.

The lack of fluidity we observed when discussing process seemed to roughly correspond with how junior the faculty member was, suggesting that developing metacognitive awareness of one's own mindsets and approach to doing research happens gradually over time as many research projects are completed.

\section{Reflecting on Mentoring}

The researchers displayed a similar variability in their ability to talk reflectively about their mentoring approaches as about their own research process. Again, it was the senior scholars (and the same junior scholar in education) who were able to - with some thinking aloud - describe the mindsets they seek to instill in their students and the concrete practices they engage in to do so. More often, the junior faculty struggled with the questions about mentoring. Examples from two ends of the spectrum will illustrate this variation. 
One junior social scientist had been quite reflective when discussing research practice, but shifted to talking almost exclusively about analytic aspects of research (choosing the right method) when we asked about specific aspects he tries to model or demonstrate:

"Hmmm....it'd be interesting to ask our students that...um...hmmm....I mean a lot of that depends on the nature of the question. For us a lot of that would have to do with differences in methodological approaches they might be using to collect data, so I don't know... I think if the question is clear which is really hard and if it's a question that a student is keenly interested in figuring out then methods are entirely contingent on nature of that question."

In contrast, a senior public policy scholar thought for a second then described two aspects that he had previously mentioned as part of his own creative process:

"One of them is creating the internal capacity to learn enough about another discipline or field or area of research so you can engage. Having the patience to do it and willingness to be, what would the word be, to get below a surface level and genuinely learn enough so you're a credible communicator. You don't have to know everything but...I do try to model that but I do think it's essential....you don't know something until you're able to explain it someone else well, my mother taught me that...I firmly believe that. We operate in a world where problems are too big and too important to not treat them with seriousness and importance they deserve. And people are like that too. It's almost a respect for the problem and the individuals you're going to be engaging that you need to do that.

The other thing I do try to model is this analogy stuff...I do that a lot in class, 'so what is this like, what other instances have you seen that are kind of like this?' and I don't always have something in mind, I don't always have the answer but it's like learning a different creative process and trying to free yourself to ask weird questions like that. I think that's important to model because you get out into the real world and you know a smidgen of the answers."

In contrast to the social scientist, the public policy scholar has a conscious sense of the attitudes that underlie his research and some awareness of how they influence his interactions with students.

Of course, we are assuming that greater ability to describe one's mentoring approach and practices results in more thoughtful mentoring. As one junior faculty member pointed out, however, "modeling is happening whether you know it or not." It might be that some of the scholars are acting in ways they cannot describe in words. However, given the observations of students we have taught (a subset of whom are advised by scholars in this study), it might also be that some of the practices that the junior (and sometimes senior) researchers use in their own work are not being adequately translated through their interactions with their students.

The four senior scholars all brought up creativity as something they seek to instill in their students. One captured this sentiment when he stated, "[dissertation writing] is just a creative process; it's not always predictable." (Recall we had intentionally not mentioned creativity until the end of the interview protocol, so these mentions were spontaneous). Each described the need for students to engage in a discovery process to frame their research questions, but the way they mentored students to do this was shaped by how the scholar themselves approached research practice. For instance, the public policy scholar quoted above described how he saw his role:

"I ask a lot of questions not to put the person on the spot but first I want to understand have they formulated a question or set of questions they're passionate about and if so, lay them out, do they look like they're going to be fruitful in terms of research trajectories. And then how can I help them think about things that they haven't already thought about with those questions. And then there are some students that come in and they haven't really articulated their questions well yet, they actually have very amorphous ideas about what they want to do and that's way harder in a way because you want them to actually glom onto something or a 
set of questions that they can feel passionate about... [T] he amorphous stuff is to me most challenging. It's a process of discovery that takes a lot of time... often I look to push the person out and just network them with a bunch of interesting people who have interesting problems that are somewhere in that universe that they've articulated so that they can start to understand what real problems are and worldviews and hone in on what their question is. I think also that my job is to help them see connections that they haven't seen already and to question connections that they absolutely think are there...I think it's a little disruptive but it's intentionally disruptive...I've had students walk into my office and say here's my hypothesis and I'm like well why do you think that and I just keep asking why."

In his own research this scholar had described finding problems by asking people in the real world and seeking to understand their perspectives. Thus his mentoring approach mirrored his own practice.

Similarly, a humanities scholar had previously described how he reads around a topic to find new projects; his mentoring consists of "long conversations from my knowledge of what are most promising" in what students had been reading. A physical sciences professor also has extensive conversations with his students, but he focuses on brainstorming, echoing his own approach. His projects have often come from brainstorming with people from other disciplines, and he tries to help his students do the same:

"The brainstorming in other communities...that's a little harder thing for one graduate student to do but putting together an interdisciplinary committee and getting them to actually brainstorm about something, setting up a situation of let's get these people in the room and talk about this... I think that's a way to start [finding a question]."

For both of these senior scholars, their own research practice also informs their mentoring approach.

While these senior faculty have general approaches, they also recognize that mentoring doctoral students is an idiosyncratic endeavor. One physical scientist summed this up when he stated

"as you become attentive to the students then somehow there's a pattern and that's what generally works... I've had $20 \mathrm{PhD}$ students and I have maybe 10 in the process and the process has never been the same. Because the topics are different, the research questions are different, the collaborations are different, sometimes it's just the student and me but most of the time it's with a team or co-advisors so what role is the co-advisor playing and how can you be complementary to that? And then the personalities are completely different."

It seems likely that senior scholars are able to reflect on the mentoring enterprise simply by virtue of their greater experience. Lovitts (2001) found that advisors who had advised many PhD students (what she calls "high-PhD-productive faculty") possessed qualitatively different attitudes and had different ways of interacting with their students than those who had advised fewer students. As the above quote from this senior physical scientist emphasizes, greater experience gives a professor greater exposure to variations and thus greater ability to distill understanding of what is commonwithin graduate education, within a given discipline, and within a given university.

\section{Conclusion and Implications}

The study reveals that despite different backgrounds, innovative interdisciplinary scholars share several mindsets and behaviors. The study participants pointed out that creativity is central to producing innovative research. In particular, they described a creative process of finding a unique way of asking a research question or designing a study followed by an analytic phase using common methods and best practices in their respective disciplines. The scholars in this study presented a picture of research practice richer than what is often presented to students in courses, books, and published accounts of research. These researchers clearly emphasized how closely creativity and science are linked and differentiated between appropriate times for analytic and creative thinking. They displayed a growth 
mindset and learning orientation, viewing failure as a learning opportunity and consciously iterating "learning by doing." They rarely felt stuck in the face of the risk and ambiguity that inevitably accompany original research.

While the scholars were conscious enough of their practice to describe these mindsets and behaviors when thinking about specific projects or with prompting, more junior and more senior scholars differed in their metacognitive awareness of these traits as part of their image of what research is. The more junior scholars seemed to be "unconsciously competent" as scholars and remained unaware of how sophisticated a set of strategies and attitudes they have developed for managing the research process. The same split between junior and senior scholars was observed in discussing mentoring. While the junior scholars may be modeling more than they realized, it is only the senior scholars who consciously perceived and could describe the patterns in their mentoring philosophy and practice.

Several implications emerge from this study. One is to make administrators, advisors, and their students aware of the subtle de-emphasis of creativity and mindfulness of process in how the research process is often discussed and depicted. Graduate school is a time of transitioning from performing as a student to embracing a learning orientation as an independent scholar. As important as it is that students learn concrete analytic techniques, it is even more important that they graduate with the competence to undertake independent research. A vital part of the experience of being a scholar is the messiness, uncertainty, ambiguity, and exhilaration of creative work (Beveridge, 1980). Successful scholars must not only develop analytic rigor to analyze data in the tradition of their chosen field but, even more importantly, must develop the creative confidence to ask engaging new questions and design innovative combinations of questions and methods, finding what one of our participants called their own "special angle of attack." These interviews suggest that one of the competencies that innovative scholars possess is a nuanced understanding of scientific creativity as an upfront research design process of generating new questions followed by the more commonly discussed process of answering those questions with analytic rigor. Introducing more balanced doctoral courses with explicit emphasis on creative problem solving and nurturing the mindsets and behaviors leading scholars possess would portray a more holistic and realistic view of what doing innovative research really means, complementing the modeling that students might or might not already be absorbing from their mentors.

Our interviewees agreed that one of the most creative aspects of research is in the initial framing of a project; finding a question is also the stage given the least attention in most research design texts and many courses, perhaps because it is an idiosyncratic and creative rather than analytic process. While accomplished scholars know from experience that this stage is not linear and relies on serendipity and intuition as well as analytic rigor, those newer to the research process may not be aware that the doubts or sense of chaos they are experiencing are normal nor know to be on the lookout for moments of happenstance because the dominant perspective on doing research they are often exposed to is linear, not contingent. Overall, the view of research presented by our investigation suggests that advisors would do their students a service by being more explicit about how they actually experience research and by providing mentoring in the techniques they have developed for sorting through the complexity of the process. Currently, discussions of emotions in research and graduate education are often dismissed as mental health or work-life issues rather than being treated as determinants of research productivity (e.g., Hyun, Quinn, Madon, \& Lustig, 2006). Coaching in the attitudes needed to remain open to new insights in the face of setbacks and to tolerate ambiguity would also be useful.

The scholars we interviewed present a different picture of scientific creativity than the one that tends to show up in graduate seminars, research design manuals, and - too often - mentoring of emerging scholars. The contrast between the two suggests that it would be useful for advisors to pay more attention to how they discuss their own creative process with their mentees. Simply discussing research as creative work would represent a significant cultural shift in many labs and departments. Mentors could share stories about the genesis of their project ideas and the concrete techniques they use to re- 
frame ideas into feasible research designs. Incorporating such stories into department seminars, lab meetings and advising sessions would be an important first step to making emerging scholars more conscious of the creative aspects of doing research. Greater ability to reflect on where one is within the research process and what to expect at each step in turn appears important for helping students cope with the anxiety that graduate school and a dissertation-sized project often inspire.

Thomas Edison suggested that genius was ninety-nine percent perspiration and one percent inspiration. The stories shared with us by the Stanford University scholars we interviewed confirm this definition of innovation. The hard background work prepares the mind for flashes of insight. The creative flashes occur primarily in the research design phase, where one designs a "special angle of attack" that shapes the analytic trajectory of a project. Being more explicit in our discussions of research about when and how one seeks inspiration and when one should expect mostly linear hard work could help emerging scholars better manage their own research processes.

Finally, this study suggests that curriculum might be developed that explicitly teaches creative problem solving, reflective practice and mindfulness of one's own research process. In engineering, product design, and other areas of innovation, the design thinking framework (Rauth, Köppen, Jobst, \& Meinel, 2010) has been used to develop innovation mindsets and skills. The current study suggests that successful scholars share similar mindsets and behaviors to designers, such as creative confidence, viewing failure as an opportunity and use of iteration. While the day-to-day experiences that researchers generally think about as "doing research" often do not resemble the work of designers (though scholars in disciplines such as engineering and applied biochemistry may work in similar ways), design thinking may be a useful tool to help graduate students become more mindful of their own research process and develop skills for creative problem solving. We have developed a workshop curriculum (Ulibarri, Cravens, Svetina Nabergoj, Cornelius, \& Royalty, 2014) that uses design thinking pedagogy to help graduate students be more mindful of their own research process and more aware of the role of creativity in their scholarly work. Students have found these workshops a breath of fresh air, further emphasizing the contrast between how advisors consciously discuss and model the research process and how the innovative scholars in our study approach their own research. But the implications extend beyond just doctoral students as we have seen increasing interest to participate in these workshops among junior faculty members, suggesting that training in creative problem solving might also help them in developing their metacognitive awareness of their research approach as well as their mentoring skills.

This study of innovative scholars also suggests directions for future research. One, we did not investigate how the participants in our sample developed their own research practice; it would be interesting to explore their relationships with their advisors and how they were trained in order to understand how training influences later practice and mentoring. Two, while it was inspired by reports from doctoral students we taught, the current study relies on interviews with professors. A follow-up study could interview their students, in order to correlate professor reports of their mentoring approaches with student reports of the advising experience. It is possible that advisors are modeling more than they are consciously aware about the research process, though the reports from our workshops suggests that there are widespread elements being missed in mentoring. Finally, we would like to expand this study to professors and students beyond Stanford University. As a world-class research institution, this university has particular characteristics that may not generalize, including high demands on professor time that can impact time and energy available for mentoring and plentiful resources for developing research and interdisciplinary collaborations. 


\section{References}

Anderson, B., Cutright, M., \& Anderson, S. (2013). Academic involvement in doctoral education: Predictive value of faculty mentorship and intellectual community on doctoral education outcomes. International Journal of Doctoral Studies, 8, 195-201. Available at http://ijds.org/Volume8/IJDSv8p195215Anderson0405.pdf

Barnes, B. J., \& Austin, A. E. (2009). The role of doctoral advisors: a look at advising from the advisor's perspective. Innovative Higher Education, 33(5), 297-315. doi:10.1007/s10755-008-9084-x

Beveridge, W. I. B. (1980). Seeds of discovery: A sequel to the art of scientific investigation. New York: Norton.

Boyack, K. W., Klavans, R., \& Börner, K. (2005). Mapping the backbone of science. Scientometrics, 64(3), $351-374$.

Broussine, M., \& Ahmad, Y. (2013). The development of public managers' reflexive capacities. Teaching Public Administration, 31(1), 18-28. doi:10.1177/0144739412466866

Brown, T. (2008). Design thinking. Harvard Business Review, 86(6), 84-92, 141.

Budner, S. (1962). Intolerance of ambiguity as a personality variable. Journal of Personality, 30(1), 29-50.

Bulman, C., Lathlean, J., \& Gobbi, M. (2012). The concept of reflection in nursing: Qualitative findings on student and teacher perspectives. Nurse Education Today, 32(5), e8-13. doi:10.1016/j.nedt.2011.10.007

Cash, T. F., \& Sanchez-Hucles, J. (1992). The dissertation in professional psychology programs: II. Model and evaluation of a preparatory course. Professional Psychology: Research and Practice, 23(1), 63-65. doi:10.1037/0735-7028.23.1.63

Castro, V., Garcia, E. E., Cavazos, Jr., J., \& Castro, A. Y. (2011). The road to doctoral success and beyond. International Journal of Doctoral Studies, 6, 51-77. Available at http://ijds.org/Volume6/IJDSv6p051077Castro310.pdf

Chan, A. W. (2008). Mentoring ethnic minority, pre-doctoral students: An analysis of key mentor practices. Mentoring \& Tutoring: Partnership in Learning, 16(3), 263-277. doi:10.1080/13611260802231633

Council of Graduate Schools in the United States. (1977). The doctor of philosophy degree: A policy statement. Washington, DC: Council of Graduate Schools in the United States.

Davis, M. L., Thwaites, R., Freeston, M. H., \& Bennett-Levy, J. (2014). A measurable impact of a selfpractice/self-reflection programme on the therapeutic skills of experienced cognitive-behavioural therapists. Clinical Psychology \& Psychotherapy. doi:10.1002/cpp.1884

Dweck, C. S. (2006). Mindset: The new psychology of success. New York: Random House.

Evans, A. (2013). Best practices: Australian clinical legal education. The Law Teacher, 47(3), 421-423. doi:10.1080/03069400.2013.852002

Flyvbjerg, B. (2006). Five misunderstandings about case-study research. Qualitative Inquiry, 12(2), 219-245. doi:10.1177/1077800405284363

Gardner, S. K. (2008). "What's too much and what's too little?" The process of becoming an independent researcher in doctoral education. The Journal of Higher Education, 79(3), 326-350. doi:10.1353/jhe.0.0007

Gardner, S. K. (2010). Faculty perspectives on doctoral student socialization in five disciplines. International Journal of Doctoral Studies, 5, 39-53. Available at http://ijds.org/Volume5/IJDSv5p039053Gardner293.pdf

Guest, G., MacQueen, K. M., \& Namey, E. E. (2011). Applied thematic analysis. Los Angeles: SAGE Publications, Inc.

Heinze, T., \& Bauer, G. (2007). Characterizing creative scientists in nano-S\&T: Productivity, multidisciplinarity, and network brokerage in a longitudinal perspective. Scientometrics, 70(3), 811-830.

doi:10.1007/s11192-007-0313-3 
Heinze, T., Shapira, P., Rogers, J. D., \& Senker, J. M. (2009). Organizational and institutional influences on creativity in scientific research. Research Policy, 38(4), 610-623. doi:10.1016/j.respol.2009.01.014

Heinze, T., Shapira, P., Senker, J. M., \& Kuhlmann, S. (2007). Identifying creative research accomplishments: Methodology and results for nanotechnology and human genetics. Scientometrics, 70(1), 125-152.

Hemlin, S., Allwood, C. M., \& Martin, B. R. (Eds.). (2004). Creative knowledge environments: The influences on creativity in research and innovation. Northhampton, MA: Edward Elgar.

Hollingsworth, J. R. (2002). Research organizations and major discoveries in twentieth-century science: A case study of excellence in biomedical research. Wissenschaftszentrum, Berlin.

Hollingsworth, J. R. (2012). Factors associated with scientific creativity. Euresis, 2, 77-112.

Hyun, J. K., Quinn, B. C., Madon, T., \& Lustig, S. (2006). Graduate student mental health: needs assessment and utilization of counseling services. Journal of College Student Development, 47(3), 247-266. doi:10.1353/csd.2006.0030

Kelley, T., \& Kelley, D. (2013). Creative confidence: Unleashing the creative potential within us all. New York: Drown Business.

LaBoskey, V. K. (2010). Teacher education and models of teacher reflection. In P. Peterson, E. Baker, \& B. McGaw (Eds.), International encyclopedia of education (Third Edition., pp. 629-634). Oxford: Elsevier. Retrieved from http://www.sciencedirect.com/science/article/pii/B9780080448947006692

Lovitts, B. E. (2001). Leaving the ivory tower: The causes and consequences of departure from doctoral study. Lanham, MD: Rowman \& Littlefield Publishers.

Lovitts, B. E. (2005). Being a good course-taker is not enough: A theoretical perspective on the transition to independent research. Studies in Higher Education, 30(2), 137-154. doi:10.1080/03075070500043093

Lovitts, B. E. (2008). The transition to independent research: Who makes it, who doesn't, and why. The Journal of Higher Education, 79(3), 296-325. doi:10.1353/jhe.0.0006

Lyons, N. (Ed.). (2010). Handbook of reflection and reflective inquiry: Mapping a way of knowing for professional reflective inquiry. Boston, MA: Springer Science+Business Media, LLC.

Metcalfe, J., \& Shimamura, A. P. (1994). Metacognition: Knowing about knowing. Cambridge, Mass.: MIT Press.

Mohan, V. V. (2010). Mentoring doctoral students in a developing society. Issues in Informing Science and Information Technology, 7, 249-264. Available at http://iisit.org/Vol7/IISITv7p249-264Mohan746.pdf

Morillo, F., Bordons, M., \& Gómez, I. (2003). Interdisciplinarity in science: A tentative typology of disciplines and research areas. Journal of the American Society for Information Science and Technology, 54(13), 1237-1249. doi:10.1002/asi.10326

Nussbaum, B. (2004). The power of design. Business Week, 17.

Pea, R., Mills, M., Rosen, J., Dauber, K., Effelsberg, W., \& Hoffert, E. (2004). The Diver project: Interactive digital video repurposing. IEEE MultiMedia, 11(1), 54-61. doi:10.1109/MMUL.2004.1261108

Rauth, I., Köppen, E., Jobst, B., \& Meinel, C. (2010). Design thinking: an educational model towards creative confidence. Proceedings of the 1st International Conference on Design Creativity ICDC 2010. Kobe, Japan. Retrieved from http://papers.designsociety.org/design thinking an educational model towards creative confidence.pape r.30267.htm

Sawyer, R. K. (2006). Educating for innovation. Thinking Skills and Creativity, 1(1), 41-48. doi:10.1016/j.tsc.2005.08.001

Schön, D. A. (1983). The reflective practitioner: How professionals think in action. New York: Basic Books.

Schön, D. A. (1990). Educating the reflective practitioner. San Francisco: Jossey-Bass. 
Simonton, D. K. (2004). Creativity in science: Chance, logic, genius, and Zeitgeist. Cambridge, UK; New York: Cambridge University Press.

Spaulding, L. S., \& Rockinson-Szapkiw, A. J. (2012). Hearing their voices: Factors doctoral candidates attribute to their persistence. International Journal of Doctoral Studies, 7, 199-219. Available at http://ijds.org/Volume7/IJDSv7p199-219Spaulding334.pdf

Stokols, D., Hall, K. L., Taylor, B. K., \& Moser, R. P. (2008). The science of team science: Overview of the field and introduction to the supplement. American Journal of Preventive Medicine, 35(2 Suppl), S77-89. doi:10.1016/j.amepre.2008.05.002

Strober, M. H. (2011). Interdisciplinary conversations: Challenging habits of thought. Stanford, CA: Stanford University Press.

Tegano, D. (1990). Relationship of tolerance of ambiguity and playfulness to creativity. Psychological Reports, $66,1047-1056$.

Ulibarri, N., Cravens, A. E., Cornelius, M., Royalty, A. \& Nabergoj, A. S. (2014). Research as design: Developing creative confidence in doctoral students through design thinking. International Journal of Doctoral Studies, 9, 249-270. Retrieved from http://ijds.org/Volume9/IJDSv9p249-270Ulibarri0676.pdf

Uzzi, B., \& Spiro, J. (2005). Collaboration and creativity: The small world problem. American Journal of Sociology, 111(2), 447-504. doi:10.1086/ajs.2005.111.issue-2

Van Leeuwen, T., \& Tijssen, R. (2000). Interdisciplinary dynamics of modern science: Analysis of crossdisciplinary citation flows. Research Evaluation, 9(3), 183-187. doi:10.3152/147154400781777241

Van Raan, A. F. J. (2000). The interdisciplinary nature of science: Theoretical framework and bibliometricempirical approach. In N. Stehr \& P. Weingart (Eds.), Practising interdisciplinarity (pp. 66-78). Toronto: University of Toronto Press.

Watkins, C. (2010). Learning, performance and improvement. INSI Research Matters, 34.

Weidman, J. C., Twale, D. J., \& Stein, E. L. (2001). Socialization of graduate and professional students in higher education: A perilous passage? (ASHE-ERIC Higher Education Report No. Volume 28, Number 3). Washington, DC: ERIC Clearinghouse on Higher Education. Retrieved from http://eric.ed.gov/?id=ED457710

Zuckerman, H. (1996). Scientific elite: Nobel laureates in the United States. New Brunswick, NJ: Transaction Publishers.

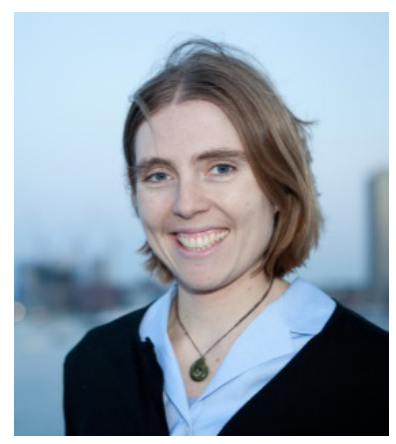

\section{Biographies}

Amanda E. Cravens is a postdoctoral researcher at Stanford University. Trained as an interdisciplinary social scientist, she is broadly interested in how groups of people learn, negotiate, and make decisions together. Her current research is investigating how using information technology influences public policy decision making. As a teacher she has developed and evaluated experiential learning curricula for environmental policy, negotiation, and research design courses. 


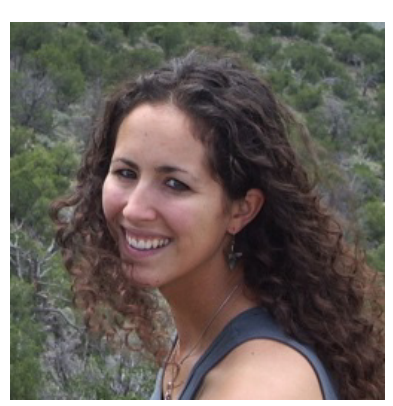

Nicola Ulibarri is a doctoral candidate in the Emmett Interdisciplinary Program in Environment and Resources at Stanford University. Her research uses political, social, and technical perspectives to evaluate the sustainability of environmental planning and decision-making practices, with a focus on collaborative governance and water resources management.

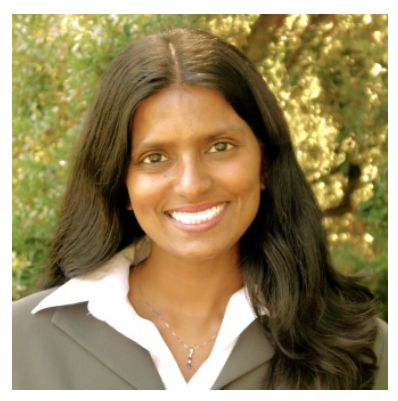

Marilyn Cornelius is Principal Consultant and Managing Director at d.cipher pathways, LLC. She holds a doctorate from the Emmett Interdisciplinary Program in Environment and Resources (E-IPER) at Stanford. Her research interests are in designing behavioral solutions to reduce greenhouse gas impacts related to energy use, food, and transportation in the residential sector, including designing, implementing, and evaluating a behavior change curriculum for high school.

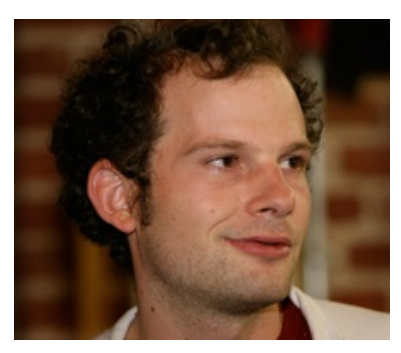

Adam Royalty is the Lead Design Research Investigator at the Hasso Plattner Institute of Design (d.school) at Stanford University. His research focuses on how to authentically measure the impact of human centered design. Since joining the d.school, Adam has taught multiple design thinking courses and has worked to deepen the creative capacity of organizations in a dozen countries. Prior to his role as a researcher, he led education projects in the d.school's K-12 Lab. Adam holds an MA in Learning, Design, and Technology from Stanford University.

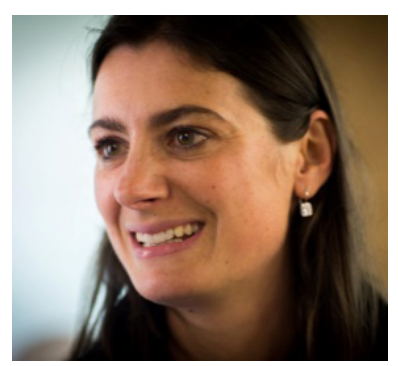

Anja Svetina Nabergoj is an Assistant Professor at the Faculty of Economics, University in Ljubljana in Slovenia, where she teaches undergraduate and graduate entrepreneurship courses. Her main focus is developing and using design thinking methodology and adapting it for entrepreneurship courses and business school curriculum. She is also a Lecturer at Stanford University's Hasso Plattner Institute of Design. In her work she focuses on helping individuals, teams and organizations build their creative confidence. Her recent research focuses on design thinking, primarily in the context of entrepreneurship education and doctoral studies. 